\title{
Usage Of Zeolite And Chitosan Composites As Slow Release Fertilizer
}

\author{
*Dina Kartika Maharani, Kusumawati Dwiningsih, Raisza Tarida Savana, Puma Manggala Virga Andika \\ Department of Chemistry, Universitas Negeri Surabaya, Surabaya, Indonesia \\ *dinakartika@unesa.ac.id
}

\begin{abstract}
The research with the title usage of zeolite and chitosan composites as slow release fertilizer had been done. In this research, fertilizer was made by mixing zeolite with $\mathrm{NaNO}_{3}$ as a source of macro nutrients (nitrogen) and chitosan as a crosslinks which will later be used to provide slow release function in fertilizers. The slow release fertilizer was made by impregnating zeolite on $\mathrm{NaNO}_{3}$ and chitosan solution. Initial characterization of slow release fertilizer functional groups was identified using FTIR instruments. The results of the characterization of slow-release fertilizer functional group are known to have shifted the zeolite characteristic peaks namely Si$\mathrm{O}$ and $\mathrm{Al}-\mathrm{O}$ groups which indicate the presence of Nitrogen got into the fertilizer. Nitrogen release rates were identified by $\mathrm{UV}$ VIS spectrophotometer. The slowest Nitrogen release rate is zeolite-chitosan fertilizer with the ratio of zeolite and chitosan is 1:1 $(\% \mathrm{w} / \mathrm{w})$, while the fastest Nitrogen release produced by zeolite fertilizer.
\end{abstract}

Keywords - slow release fertilizer, chitosan, zeolite, composites.

\section{INTRODUCTION}

Agricultural productivity is very dependent on the fulfillment of nutrients needed by plants. The fulfillment of plant nutrition can be done by fertilizing. Fertilizers are added to the soil to release nutrients needed for plant growth. The most needed nutrients for plant growth are nitrogen. However, only $30 \%$ of nitrogen nutrients in fertilizers can be absorbed by plants while the rest is lost [1]. Lack of basic nitrogen nutrients in plants can cause plants to not grow properly. The loss of nitrogen in fertilizers is caused by nitrogen which is easily released in the form of nitrate $\left(\mathrm{NO}_{3}^{-}\right)$, evaporates into the air as an ammonia gas $\left(\mathrm{NH}_{3}\right)$, so that $\mathrm{N}_{2} \mathrm{O}$ emissions will have an impact on the environment [2].

One of ways to increase the efficiency of uptake of nitrogen and reduce the impact of environmental pollution due to excess nitrogen is by making fertilizer in the form of slow release [3]. This slow-release fertilizer is able to provide nutrients more efficiently so that plants will be absorbed more slowly through the release process. The principle of slowing the release of nutrients in slow-release fertilizers can be done in various ways, one of which is by regulating the solubility of fertilizer in water with the addition of other ingredients [4].

Materials that are often added to slow release fertilizer are polymers, sulfur, superabsorbent materials, and bio composites. The use of sulfur in fertilizers has a disadvantage because sulfur is not easily biodegradable in the soil, and excess amounts of sulfur can make the soil more acidic, so that it can also pose a risk of environmental pollution [5]. The use of synthetic polymers such as polyethylene, polyvinyl chloride [6], polysulfide [7], and polystyrene [8] on the manufacture of slow-release fertilizers has the potential to become new pollutants because the remaining polymer materials are difficult to decompose and will accumulate in the soil from time to time. Natural polymers are one of the breakthroughs in the manufacture of slow-release fertilizers because they are more environmentally friendly such as starch, lignin and cellulose. However, the hydrophilic nature of the material cannot be used as a single ingredient for fertilizer and requires mixing with other materials for more effective use [5].

Zeolites and chitosan are natural polymer materials that have the potential to produce fertilizer slowly because they are hydrophobic and environmentally friendly. Zeolite in general can be used to increase bioactivity on the soil, reduce evaporation of ammonia and increase the retention capacity of nutrient release in the soil [9]. Chitosan can be used as a physical barrier to fertilizers which can reduce the rate of diffusion of water into core fertilizer and diffusion of nutrients beyond the core fertilizer [10]. Therefore, the manufacture of zeolite and chitosan-based slow-release fertilizers has the potential to produce fertilizer with slowed release of nutrients which means that it can reduce environmental pollution due to excess nitrogen. In the study, zeolite-based slow release fertilizers were composted with $\mathrm{NaNO}_{3}$ and chitosan.

\section{RESEARCH METHOD}

\section{A. Equipment and Materials}

The equipment that used in this research are hot plate stirrer, porcelain cup, mortar, watch glass, petri dish, stainless steel clamp, mercury thermometer, analytical balance, blender, oven, electric stove, dip coater tool, 80 mesh sieve, sonication, centrifuge, Fourier Transform Infra-Red Spectroscopy (FTIR) (Shimadzu). Materials that used in this research are zeolite, chitosan, $\mathrm{HCl}$ (Merck), $\mathrm{CH}_{3} \mathrm{COOH}$ p.a (Merck), ethanol p.a (Merck), technical ethanol, $\mathrm{NaNO}_{3}$, indicator paper $\mathrm{pH}$, distilled water, and Aqua deionization.

\section{B. Method}

Zeolite is activated using $1 \mathrm{M} \mathrm{HCl}$ solution by stirring for 30 minutes using a constant speed, then filtered with filter paper and oven at $105{ }^{\circ} \mathrm{C}$ for 2 hours. Dry zeolite is then washed with distilled water and checked with $\mathrm{AgNO}_{3}$ solution until there is no residual $\mathrm{HCl}$. Slow release fertilizer was made by mixing $5 \% \mathrm{NaNO}_{3}$ solution with zeolite and chitosan as much as 1 gram each and stirring for 3 hours at room 
temperature. Then filtered with a vacuum Buchner funnel and dried at $105^{\circ} \mathrm{C}$ for 2 hours.

Slow release fertilizer powder is slowly evaporated in an oven to dry at a temperature of $60{ }^{\circ} \mathrm{C}$. The composite powder obtained was then ground with mortar, sieved and analyzed by FTIR spectrophotometry. Then a total of 10 grams of slowrelease fertilizer is put into a glass beaker containing 100 grams of soil and added with $180 \mathrm{ml}$ of distilled water. Furthermore, the collected water was measured for nitrogen levels every 24 hours for 7 days.

\section{RESULTS AND DISCUSSION}

\section{A. Slow Release Fertilizer Preparation}

Slow release fertilizer is prepared by impregnation method of nitrogen element source into zeolite powder. Zeolite was first sieved with a size of 60 mesh to increase the homogeneity of the mixture and increase the surface area. The zeolite is then activated with $\mathrm{HCl}$ in order to open the zeolite pores so that the adsorption process takes place more effectively. The zeolite which has been activated is then impregnated into $\mathrm{NaNO}_{3}$ solution as a nitrogen nutrient source. $\mathrm{NaNO}_{3}$ solution will be trapped into zeolite pores through physical interaction so that nitrogen zeolite composites will be formed [9]. Addition of chitosan to nitrogen zeolite composite fertilizer was carried out to modify the surface structure to improve hydrophobicity. Chitosan and zeolite generally will interact through hydrogen bonds between their functional groups, namely Si-O and Al-O groups in zeolites with $\mathrm{NH}_{2}$ groups in chitosan. Zeolite as a matrix will fill the chitosan substrate.

Slow release fertilizers made in this study include Nitrogen Zeolite fertilizer, Nitrogen chitosan zeolite fertilizer and Nitrogen Zeolite-Chitosan fertilizer. Nitrogen Zeolite fertilizer has greenish color according to zeolite color, while chitosan fertilizer is brownish white because of chitosan color and fertilizer color. Chitosan nitrogen zeolite is green. Data analysis of impregnated nitrogen levels on zeolite fertilizer, chitosan fertilizer and zeolite-chitosan fertilizer was carried out using UV VIS spectrophotometry method. The results of Nitrogen element analysis in fertilizer samples are presented in Table I.

TABLE I. NITROGEN ANALYSIS ON FERTILIZERS

\begin{tabular}{|c|c|c|c|}
\hline Sample & $\begin{array}{c}\text { Initial N } \\
(\mathbf{m g} / \mathbf{L})\end{array}$ & $\begin{array}{c}\text { N remains } \\
(\mathbf{m g} / \mathbf{L})\end{array}$ & $\begin{array}{c}\text { Impregnated } \\
\mathbf{N}(\mathbf{m g} / \mathbf{L})\end{array}$ \\
\hline Zeolite & 50 & 4.01 & 545.99 \\
\hline Chitosan & 50 & 5.29 & 544.71 \\
\hline $\begin{array}{c}\text { Zeolite-Chitosan } \\
\text { (ZK) (1:1) }\end{array}$ & 50 & 3.55 & 546.45 \\
\hline $\begin{array}{c}\text { Zeolite-Chitosan } \\
\text { (ZK) (1:2) }\end{array}$ & 50 & 3.47 & 546.53 \\
\hline $\begin{array}{c}\text { Zeolite-Chitosan } \\
\text { (ZK) (2:1) }\end{array}$ & 50 & 2.81 & 547.19 \\
\hline
\end{tabular}

Nitrogen content analysis results showed that the impregnation process of $\mathrm{NaNO}_{3}$ solution was successfully carried out. Nitrogen element content that enters zeolite, chitosan and chitosan zeolite composite is $>90 \%$. In zeolite and chitosan, the amount of Nitrogen entering is higher than in zeolite-chitosan composites. This is possible for zeolite-chitosan composites to change pores and crystallinity of composites so as to influence the amount of Nitrogen elements that can enter.

\section{B. Slow Release Fertilizer Characterization}

Fertilization characterization was carried out using FTIR to analyze functional groups. The results of the characterization of the slow release fertilizer functional group are shown in Figure 1. Based on the zeolite FTIR spectra and slow release fertilizer in Figure 1, the peak is seen in the wave number area of $3500-3200 \mathrm{~cm}^{-1}$ which shows the absorption of $\mathrm{OH}$ groups in the zeolite and the absorption of moisture entering the zeolite pores. The peaks that appear in the wave number 1053 $\mathrm{cm}^{-1}$ and $794.7 \mathrm{~cm}^{-1}$ show bending and stretching of $\mathrm{Si}-\mathrm{O}$ and Al-O. OH uptake appeared in the wave number $3421 \mathrm{~cm}^{-1}$ and $3634 \mathrm{~cm}^{-1}$. The peaks experienced a shift in the Nitrogen zeolite composite fertilizer spectra and Nitrogen zeolite composite fertilizer with the addition of chitosan to 3450 , 1049, 793, $594 \mathrm{~cm}^{-1}$ as shown in Fig. 1.

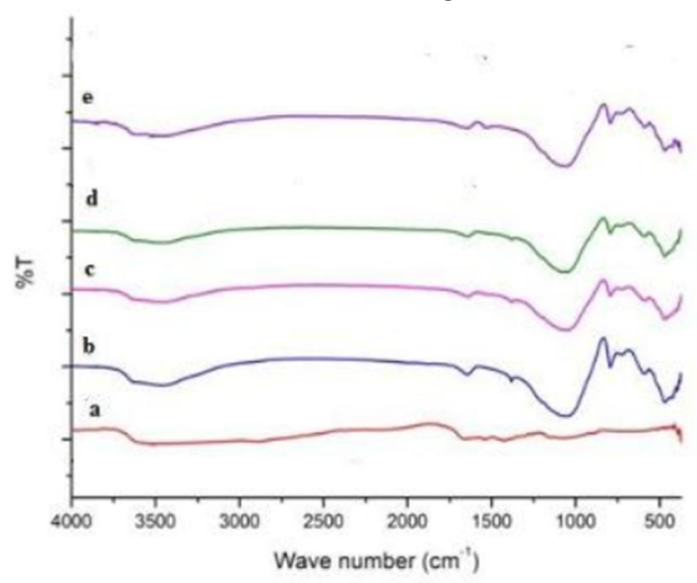

Fig.1. a). Chitosan , b). Zeolite-Chitosan (1:1), c). Zeolite-Chitosan (1:2), d). Zeolite-Chitosan (2:1), e). Zeolite

\section{Nitrogen Release Test}

Nitrogen release test in the soil is carried out for 7 days with a percolation system. Prepared soil samples are mixed with fertilizer and doused with water until the interval of 1-7 days. An image of the nitrogen release test in the soil is shown in Fig. 2.

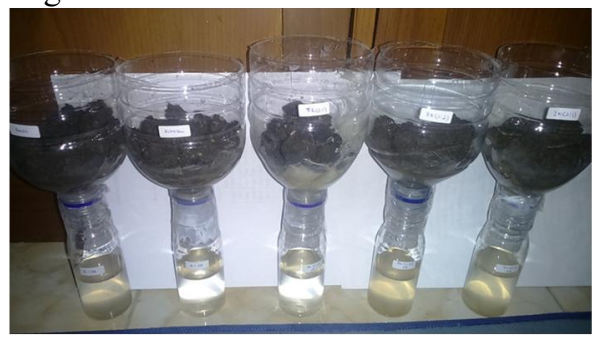

Fig.2. Nitrogen release test for zeolite fertilizer, chitosan fertilizer and zeolite chitosan fertilizer in soil

Nitrogen release test is one test that aims to determine the nitrogen content of a fertilizer, within a predetermined time period (incubation period). Nitrogen release testing was carried out using two methods, namely percolation method and kjeldahl method. The fertilizers tested in this nitrogen element release test are zeolite fertilizer, chitosan fertilizer, 1: 1 zeolite-chitosan fertilizer, 1: 2 chitosan 
zeolite fertilizer and 2: 1 chitosan-chitosan fertilizer. The results of $\mathrm{N}$ release levels for fertilizer samples are presented in Table II. Graphs of Nitrogen release during the incubation period with incubation interval in this study, namely $0,1,2,3$, $4,5,6,7,14,21$, and 28 days are presented in Fig. 3.

TABLE II. NITROGEN RELEASE LEVELS

\begin{tabular}{|c|c|c|c|c|c|}
\hline \multirow{2}{*}{ Days } & \multicolumn{5}{|c|}{ Levels (\%) } \\
\cline { 2 - 6 } & Chitosan & Zeolite & ZK (1:1) & ZK (1:2) & ZK(2:1) \\
\hline 0 & 0.0000353 & 0.0000321 & 0.0000054 & 0.0000052 & 0.0000123 \\
\hline 1 & 0.0000641 & 0.0000491 & 0.0000054 & 0.0000085 & 0.000017 \\
\hline 2 & 0.0000652 & 0.0000576 & 0.0000098 & 0.0000112 & 0.0000192 \\
\hline 3 & 0.0000677 & 0.0000661 & 0.000009 & 0.0000063 & 0.0000233 \\
\hline 4 & 0.0000754 & 0.0000718 & 0.0000043 & 0.0000041 & 0.0000244 \\
\hline 5 & 0.0000746 & 0.0000858 & 0.0000032 & 0.0000057 & 0.0000296 \\
\hline 6 & 0.0000795 & 0.0000872 & 0.0000076 & 0.0000035 & 0.0000356 \\
\hline 7 & 0.0000902 & 0.0000982 & 0.0000167 & 0.0000021 & 0.0000436 \\
\hline 14 & 0.0000869 & 0.0001037 & 0.0000222 & 0.0000161 & 0.0000537 \\
\hline 21 & 0.0000853 & 0.0001198 & 0.0000323 & 0.0000397 & 0.0000718 \\
\hline 28 & 0.0001004 & 0.0001552 & 0.0000449 & 0.0000707 & 0.0001004 \\
\hline
\end{tabular}

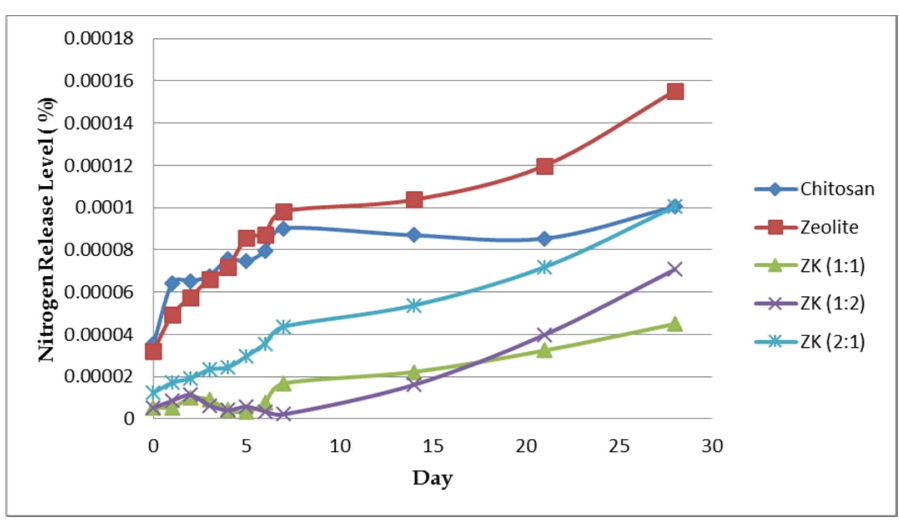

Fig. 3. Level of Nitrogen Release of Fertilizers

Based on Table 2 and Figure 3, it was found that the percentage of nitrogen levels released from the sample during the incubation period in the five samples above at the first release (day 0 ) to the twenty-eighth day (day 28) showed the levels of release that met the standards, namely with the European Standardization Committee (CEN). According to the CEN standard, the release of Nitrogen in slow release fertilizer for the day 0 release rate is not more than $15 \%$ which is released in 24 hours and the release rate on day 28 is not more than $75 \%$ [11].

The results of the release of Nitrogen in fertilizer samples in general on day 0 to day 28 for 1: 1 zeolite-chitosan fertilizer samples showed the lowest Nitrogen release results, while the highest Nitrogen release was produced from zeolite fertilizer. The release of Nitrogen content for zeolite-chitosan composite fertilizer in all comparisons of zeolite and chitosan composition, generally shows lower value than zeolite and chitosan fertilizers. This indicates that composite fertilizers from zeolite and chitosan mixtures have a greater slow release capability compared to zeolite fertilizers and chitosan fertilizers themselves. This high slow release ability can be caused by the interaction between zeolite and chitosan which forms a matrix so that nitrogen in the form of $\mathrm{NO}_{3}$ can be absorbed in the zeolite pores and bound by chitosan through electrostatic interactions, besides the superabsorbent properties of the weak hydrophilic properties of chitosan chitosan absorbs fertilizer solution in the soil longer so that the element Nitrogen in the form of $\mathrm{NO}_{3}$ can be released more slowly [10].

The release value of Nitrogen in the soil for all types of fertilizer in this study is relatively very small at around $0.0001 \%$ which means that the effectiveness of slow release of all types of fertilizer produced is quite high. This result is in line with the research of Lateef, et al, [9] who also carried out the Nitrogen release test on zeolite fertilizer alone which ranged from $0.005 \%$ Nitrogen release rate.

\section{CONCLUSION}

Conclusions from the results of this research is slow release fertilizer from zeolite and chitosan has been successfully prepared by impregnating NaNO3 solution into zeolite and chitosan. The results of the initial level analysis of impregnated nitrogen with UV VIS spectrophotometry method showed the value of Nitrogen content was $90 \%$. The results of the functional group analysis on zeolite and zeolite fertilizer and chitosan fertilizer obtained the results of a shift in wave numbers for typical peaks of zeolite and chitosan groups, $\mathrm{OH}$, $\mathrm{Si}-\mathrm{O}, \mathrm{Al}-\mathrm{O}$ and $\mathrm{NH}$ groups around wave numbers 3400,1600 , 1000,700 and $500 \mathrm{~cm}^{-1}$. The slowest Nitrogen release rate is produced by 1: $1(\% \mathrm{w} / \mathrm{w})$ zeolite-chitosan fertilizer, while Nitrogen release is the fastest produced by zeolite fertilizer.

\section{ACKNOWLEDGMENT}

The author would like to thank Prof. Dr. Suyono. M.Pd as a dean of the Faculty of Mathematics and Natural Sciences Universitas Negeri Surabaya and Prof. Dr. Suyatno., M.Si as a head of Chemistry Departmen Universitas Negeri Surabaya.

\section{REFERENCES}

[1] Trinh, T. H., Kushaari, K., Shuib, A. S., Ismail, L., and Azeem, B. . "Modelling the Release of Nitrogen from Controlled Release Fertiliser: Constant and decay release".2015. Biosystems Engineering, 130: pp.3442.

[2] González, M. E., Cea, M., Medina, J., González, A., Diez, M. C., Cartes, P., Monreal, C., and Navia, R. "Evaluation of Biodegradable Polymers as Encapsulating Agents for the Development of a Urea Controlledrelease Fertilizer Using Biochar as Support Material”. 2015. Science of the Total Environment, 505: pp.446-453

[3] Corradini, E., de Moura, M. R., and Mattoso, L. H. C. "A Preliminary Study of the Incorparation of NPK Fertilizer into Chitosan Nanoparticles". 2010. Express Polymer Letters, Vol. 4 (8): pp. 509-515

[4] Handayani, Lili. Formulasi Pupuk Lepas Terkendali Menggunakan Pelapisan Akrilik Dan Kitosan Serta Aplikasinya Pada Pembibitan Acacia crassicarpa. 2014. Thesis. Bogor: Institut Pertanian Bogor.

[5] B. Azeem., K. KuShaari., Z.B Man., A. Basit., and T.H. Thanh "Review on Materials \& Methods to Produce Controlled Release Coated Urea Fertilizer". 2014. Journal of Controlled Release, 181: pp.11-21.

[6] Hanafi, M. M., Eltaib, S. M., and Ahmad, M. B. . "Physical and Chemical Characteristics of Controlled Release Compound Fertilizer". 2000. Eur. Polym. J., 36: pp.2081-2088.

[7] Tomaszewska, M., and Jarosiewicz, A. "Use of Polysulfone in Controlled-Release NPK Fertilizer Formulations". 2002. J. Agric. Food Chem., 50: pp. 4634-4639. 
[8] Liang, R., Liu, M., and Wu, L. "Controlled Release NPK Compound Fertilizer with the Function of Water Retention". 2007. Reactive \& Functional Polymers, 67: pp. 769-779.

[9] Lateef, A., Nazir, R, Jamil, N., Synthesis and Characterization of Zeolit Nanocomposites : An Environment friendly Slow Release Fertilizer, Microporous and Miesoporouse Material, Vol. 232, pp. 174-183.
[10] Wu, L and Liu, M., Preparation and Properties of Chitosan-coated NPK Compound Fertilizer With controlled Release and water Retention, 2008. Carbohydrate Polymers, Vol. 72, pp. 240-247

[11] Trenkel M. E. "Slow and Controlled Release and Stabilized Fertilizers: An Option for Enhancing Nutrient Use Efficiency in Agriculture", 2010 International Fertilizer Industry Association (IFA) Paris, France. 